\title{
Atendimento a uma criança que relatava ver o espírito da avó
}

\author{
Therapy for a child who reported having \\ seen her grandmother's ghost
}

Almir DEL PRETTE'

\section{Resumo}

Descreve-se o atendimento de criança do sexo feminino, com queixa inicial, trazida pela mãe, de que a filha "via a avó", falecida há alguns meses. A mãe relatou também que a criança se recusava a entrar sozinha nos ambientes da casa, pois temia a presença da avó e falava sobre o assunto frequentemente. Foram realizadas duas sessões na sala de atendimento e quatro na residência da criança com participação de suas amigas, utilizando-se procedimentos de dessensibilização, modelagem, modelação e instrução, associados a atividades lúdicas, além de orientação aos familiares. Os resultados mostraram decréscimo e supressão de verbalizações sobre o espírito da avó, uso de espaços da casa antes evitados, melhora no rendimento escolar e recuperação de contatos com colegas. Um follow-up, com visita à família e entrevista com professores, evidenciou a manutenção das aquisições. São discutidas questões sobre esse tipo de queixa em nossa cultura.

Unitermos: Espírito. Orientação de pais. Procedimentos lúdicos. Terapia infantil. Terapia familiar.

\begin{abstract}
This paper presents the therapy provided to a young girl brought in by her mother for initially reporting "seeing her grandmother" who had died some months before. The mother claimed that the child refused to enter rooms in the home alone as she feared her grandmother's presence and that the child frequently mentioned the subject. Two sessions were held at the school and four at the child's home in the company of some of herfriends. Procedures involving desensitisation, modelling, shaping and instruction were incorporated into play activities, and support was offered to the child's family members. The results showed a decrease and suppression of utterances concerning the grandmother's ghost, the use offormerly-avoided spaces in the house, an improvement in school performance and the recovery of contact with friends. Follow-up carried out through a visit made to the family and the child's teachers confirmed the maintenance of the acquisitions above. We discuss issues related to such kinds of sightings in our culture.
\end{abstract}

Uniterms: Spirit. Orientation for parents. Play procedures. Child therapy. Family therapy.

Non creo en fantasmas, pero que los hay, los hay ${ }^{2}$

Fenômenos designados genericamente de espirituais vêm recebendo atenção crescente na sociedade, a julgar as bilheterias de filmes e o índice de pessoas que assistem a novelas e programas de entretenimento com essa temática. Observa-se, ainda, na mídia eletrônica (sites, blogs etc.), a divulgação de casos de "casas assombradas" e filmagens de espíritos feitas

$\boldsymbol{\nabla \nabla \nabla \nabla}$

1 Universidade Federal de São Carlos, Departamento de Psicologia. R. Alameda das Ameixeiras 60, Parque Faber, 13561-354, São Carlos, SP, Brasil. Correspondência para/Correspondence to: A. DEL PRETTE. E-mail: <adprette@ufscar.br>.

2 Expressão atribuída a Sancho Pança no livro Dom Quixote de La Mancha de Miguel de Cervantes. 
por crianças e adolescentes, com uso até mesmo do celular para registro de sombras ou luzes de "outra dimensão". Há diferentes formas da divulgação desse tema na mídia, sendo frequentemente utilizada uma linguagem repleta de superlativos, com termos que mantêm uma aura de mistério nunca elucidado, com intenção evidente de manter o expectador cativo da transmissão do próximo programa. Essa linguagem, se não for parafraseada pelos pais que, simultaneamente, deveriam esclarecer suas chaves principais, pode manter a ansiedade da criança e exacerbar suas dúvidas existenciais.

As queixas de medo na infância, especialmente associadas a circunstâncias específicas, podem ser identificadas e explicadas a partir de sua história de vida, início, antecedentes, respostas e consequentes, processo de generalização etc. Portanto, se atendida sem muita demora, respondem bem às intervenções pontuais. Todavia, quando o atendimento se faz esperar, pode ocorrer generalização da resposta para outros ambientes com outros consequentes, o que requer intervenções mais complexas e demoradas. Quando as crianças relatam ter visto um espírito ${ }^{3}$, nem sempre os pais lidam bem com esse comportamento, especialmente quando ele se torna persistente pois somam outros que podem ou não estar associados. Os pais, na maioria das vezes, relacionam o relato a: a) uma espécie de criação fantasiosa, algo do tipo "amigo oculto" que supre uma carência afetiva; b) excesso de exposição a um tipo particular de literatura ou filmes de terror; c) possível isolamento do filho em relação a seus pares; d) uma fase própria do desenvolvimento.

De todas essas suposições, a menos plausível é a que associa o relato da presença de espíritos a um período do desenvolvimento. A literatura especializada sobre o desenvolvimento humano (M. Cole \&S. R. Cole, 2003, Novak \& Peláez, 2004) não endossa essas hipóteses, ainda que aponte a influência do isolamento social da criança e do adolescente sobre sua maneira de organizar o pensamento, seu desempenho escolar e contatos sociais. Nenhum autor aceita a atribuição de relatos sobre visão de espíritos a um determinado período do desenvolvimento, mesmo porque esse é um fato que não se restringe exclusivamente à infância ou à adolescência.
Por outro lado, na perspectiva do psicólogo clínico, não se trata de demonstrar que o fenômeno se encaixa na categoria de "ver o objeto (pessoa), na sua ausência". Isso implicaria lidar com a crença do cliente sobre a sobrevivência após a morte (espírito), supondo que a mudança da afirmação "vi um espírito" (que representa a ideia da existência dessa entidade) para "não vi e nunca verei nenhum espírito" (indicativo da ideia de não existência dessa entidade) fosse suficiente como solução da queixa apresentada.

Entende-se que o atendimento deve ser focado na queixa, definida de maneira objetiva e discutida com o cliente (Edeistein \&Yoman, 2007). Na sequência dessa providência, empreende-se o diagnóstico multimodal que, conforme Z. A. P. Del Prette e A. Del Prette (2009), implica uma combinação de instrumentos por exemplo, entrevista, observação direta e informações obtidas de mais de uma fonte, como família e escola. O diagnóstico ou avaliação inicial é resultante de um levantamento dos recursos do paciente e de seu ambiente, bem como dos deficits comportamentais e dos comportamentos concorrentes aos desejáveis, ou seja, o que o cliente gostaria de fazer e o que é esperado pelo seu entorno (Conte \& Regra, 2000). A avaliação prévia deve ser seguida de outras avaliações, durante e após o encerramento do atendimento (follow-up).

Diferentemente do atendimento de adultos, a terapia infantil tem algumas particularidades que devem ser consideradas. A primeira delas é que, em geral, a criança não procura o psicólogo por si mesma, mas vem à clínica trazida por algum adulto. Isso configura duas audiências que devem ser consideradas: a criança e a família ou cuidador que a substitui.

Outras particularidades dizem respeito aos procedimentos da intervenção. Na maioria das vezes, a família precisa ser orientada e deve ser vista não apenas como parte do problema, mas também como parte da solução. Ainda que o comportamento da criança esteja submetido às mesmas leis que regem o dos demais indivíduos (a tríplice relação de contingências), a sua imersão na cultura, na fase de desenvolvimento em que se encontra, não é similar à do adulto, nem mesmo do ponto de vista legal, que Ihe dá amparo especial. Em

286 O termo espírito está sendo utilizado neste texto como equivalente a fantasma, aparição, alma etc. 
outras palavras, pode-se dizer que a forma que a criança assimila, interpreta e utiliza a cultura é diferente da do adulto, entendendo-se cultura, na perspectiva exposta por Baum (2006), como práticas aprendidas por imitação e modelação pelos grupos. Portanto, há várias culturas, e a infantil precisa ser considerada (A. Del Prette \& Z. A. P. Del Prette, 1984). Para isso, o psicólogo clínico infantil deve dispor um repertório comportamental diferenciado daquele que atende o adulto (Del Prette, 2010). Alguns desses aspectos são discutidos em estudos desse tema (Del Prette, 2006) e de temas afins (Souza \& Baptista, 2001), que não serão aprofundados aqui. Contudo, não há dúvida que o processo terapêutico de atendimento à criança segue caminhos diferentes do atendimento de adultos (Vermes, 2009).

Tendo em vista essas considerações, este estudo tem como objetivo descrever o atendimento (especialmente os procedimentos e resultados) de uma criança em idade escolar, com queixa trazida pela mãe de que ela relatava ver a avó, já falecida. Todos os cuidados éticos foram mantidos ao longo do processo de atendimento, o que compreendeu maximizar os benefícios, restringir os custos e garantir o anonimato dos participantes.

\section{Contexto e queixa}

A criança, uma menina aqui designada por Satiko, tinha oito anos de idade quando foi trazida pela mãe para "conversar com o psicólogo". A mãe havia emigrado do Japão, já adulta, juntamente com o marido. O casal possuía um sítio onde trabalhava o dia todo. Além de ajudar o marido, a mãe atendia a freguesia e cuidava das tarefas domésticas. A mãe professava o zen-budismo, mas seu marido parecia ter pouco interesse nas práticas religiosas. A casa onde residiam tinha uma varanda, sala, três quartos, um banheiro, cozinha e um cômodo anexo, usado como depósito. Tanto Satiko como seu irmão, após as tarefas escolares, tinham atividades junto aos pais, na casa ou no sítio. O atendimento psicológico da criança foi realizado em ambiente da escola que fez o encaminhamento. Ao entrar na sala, segurando a mão da filha, a mãe disse: "Satiko vê a vó dela, minha mãequefaleceu".

A partir das entrevistas com a menina e com os professores, e também a partir das observações colhidas, foi possível estabelecer uma avaliação inicial do caso.

\section{Avaliação inicial}

Satiko era considerada pelos professores como boa aluna, disciplinada, educada e atenta às aulas. No recreio, suas preferências incluíam atividades de leitura, pintura em folhas de papel e amarelinha, mais do que brincadeiras de roda, jogos com bola e as que envolviam correrias. A mãe não conseguia auxiliá-la nas tarefas escolares de casa e Satiko recorria à ajuda do irmão ou de algumas colegas que residiam nas proximidades de sua casa. A menina e as colegas se revezavam durante a semana para fazer, cada dia em uma das casas, as tarefas escolares. Segundo Satiko, as colegas gostavam de ir à sua casa também porque comiam doces japoneses. 0 Quadro 1 apresenta uma síntese da avaliação inicial e funcional a partir da queixa da cliente.

Dois itens registram somente as respostas do ambiente, sem especificar comportamentos da paciente. No primeiro item (orações da mãe), porque ele podia estar relacionado tanto à insistência da menina em relatar que via a avó, quanto à pressão que a situação exercia sobre a mãe. No segundo item, porque a menina não sabia precisar se ela própria havia contado à professora ou se isso teria sido feito por alguma de suas colegas.

Os recursos da cliente e do ambiente também foram especificados a partir das entrevistas (professores, mãe e criança) e de observações, sendo resumidos como se segue.

- Paciente: comportamentos atentivos bem estabelecidos, desempenho acadêmico compatível com a idade, comportamentos cooperativos em diferentes ambientes, comportamentos de iniciar e manter interação com adultos e pares (cumprimenta, agradece, usa o termo "por favor" ao fazer pedidos, narra acontecimentos).

- Ambiente: no cotidiano familiar, os pais de Satiko haviam estabelecido um conjunto de normas, supervisionadas pelo casal, sobre tarefas no sitio e em casa. 0 pai aparentava maior dificuldade de contato social do que a mãe, possivelmente porque trabalhava a maior parte do tempo isolado, tinha pouco domínio do português, mas era mantido informado sobre os acontecimentos pela mulher. A mãe de Satiko mantinha contato direto com a comunidade (atendia a freguesia de verduras, fazia compras e pagamentos); quando necessário, recorria à ajuda de conhecidos. Quanto à escola, dois dos professores pareciam ter assumido a tarefa de apoiar 
Quadro 1. Especificação dos comportamentos da cliente e consequências do ambiente na avaliação inicial.

\begin{tabular}{ll}
\hline Comportamentos & Ambiente \\
\hline Relata para sua mãe que vê a avó falecida & Mãe responde que isso logo vai passar \\
Insiste que vê a avó e nomeia os locais & Mãe responde que isso logo vai passar \\
Pede a presença da mãe em seu quarto ao dormir, justificando sentir medo & Mãe lhe faz companhia até ela conciliar o sono \\
Afirma ver a avó no banheiro, em seu quarto e no quarto dos pais & Mãe algumas vezes, ascende velas coloridas e faz orações \\
Dirige-se para o quarto dos pais ou do irmão, quando acorda a noite & Os pais permitem que ela durma ao lado. O irmão (quando \\
Solicita companhia de alguém para entrar em seu quarto & acorda) se aborrece e a empurra \\
$\ldots$ & Na maioria das vezes é acompanhada pela mãe ou pai; o \\
$\ldots . .$. & irmão reluta e faz brincadeiras \\
Pede para fazer as tarefas apenas na casa das colegas & Mãe continua fazendo o ritual de orações \\
Apresenta tarefas incompletas e dificuldades nas atividades escolares & Mãe é chamada para conversar com a professora \\
& Mãe explica que isso é difícil \\
\hline
\end{tabular}

a aluna. Algumas pessoas da vizinhança, provavelmente pais de colegas de Satiko, ficaram sabendo do problema. Duas apresentaram sugestões: uma que a família chamasse o padre para benzer a residência, e outra, que se levasse a menina a um centro espírita de uma cidade próxima.

\section{Sessões e procedimentos na clínica}

Nas primeiras sessões, foi possível também observar comportamentos da mãe e da criança. As sessões envolveram: a) solicitação para Satiko mostrar seu material escolar e falar sobre suas preferências de assuntos escolares; b) desafio para Satiko separar alguns brinquedos que desconhecia e adivinhar como eles eram usados (que brincadeiras geravam); c) brincadeiras com "bonecos falantes" que faziam e respondiam perguntas (papel feito primeiramente pelo terapeuta e depois por Satiko); d) solicitação para Satiko reproduzir, com giz, no piso da sala, um esquema representativo de sua casa (vista por dentro), incluindo a localização de sua cama e as coisas que mais gostava em cada ambiente.

A ajuda do terapeuta foi pequena e incluiu ajustes de dimensões dos ambientes, como, por exemplo, o tamanho da sala maior que os quartos e estes maiores que o banheiro, bem como dicas sobre onde eram guardados objetos importantes, como armário em que era guardada a mochila, peças destinadas ao serviço do chá, posição da cama no quarto etc.

Constataram-se, no repertório de Satiko, comportamentos imitativos, sensibilidade às consequências de aprovação do terapeuta (hã, hã, isso mesmo, está certo, bom, seguidos de movimentos afirmativos de cabeça, sorrisos etc.) a certos comportamentos. Foi feita uma hierarquia de medo de Satiko, do maior para o menor, para entrar e permanecer nos diferentes ambientes da casa: pouco tempo, regular e bastante tempo, com e sem a presença de outra pessoa.

Satiko relatou também seus principais interesses e objetivos no atendimento: a) saber quanto tempo um espírito permanece na casa em que residira; b) voltar a se encontrar com as amigas em sua casa, pois elas se ajudavam nas tarefas e, além disso, achava "muito legal porque elas gostavam dos doces que a mãe fazia"; c) recuperar as boas notas que tinha antes na escola.

Sobre o primeiro objetivo, optou-se por uma resposta tranquilizadora imediata, evitando, contudo, qualquer posição contrária à ideia da possibilidade de "ver um espírito". Nesse sentido, foi dito à paciente que talvez fosse melhor ela não prestar muita atenção ao espírito da avó, que possivelmente estava buscando algum lugar para ir. Quanto aos outros objetivos, foi afirmado em expressão de desafio que ela própria poderia, com sua participação no atendimento, recuperar a presença das amigas em sua casa e organizar 
um esquema de estudo para voltar a obter boa nota escolar. Em seguida, o terapeuta propôs visitas à sua casa, onde conversaria com sua mãe e também fariam outras brincadeiras, com a participação de algumas de suas amigas.

\section{Sessões e procedimentos na residência da cliente}

Foram realizadas quatro sessões na residência da paciente. Elas foram semelhantes em alguns aspectos, mas ampliavam gradualmente a exposição de Satiko aos diferentes ambientes que evitava, por exemplo, entrar no quarto, avaliar algumas alternativas e escolher local para esconder um objeto.

Na primeira sessão, foi sugerido que Satiko ficasse esperando suas colegas no portão do sítio. Esse tempo foi utilizado para orientar seus pais e irmão para: a) não fazer nenhum comentário, caso Satiko relatasse a presença da avó, devendo apenas eles se ocuparem de alguma tarefa e conversarem sobre outro assunto qualquer; b) conversar com a menina sobre assuntos diversos, mas não sobre as visões; c) que o irmão não fizesse brincadeiras sobre espíritos, porém a ajudasse quando solicitado; d) caso a menina se dirigisse à noite para a cama dos pais, a mãe deveria fazê-la retornar, acompanhando-a e permanecendo no quarto até ela conciliar o sono e nada comentar nos dias seguintes. A ênfase na orientação para conversarem bastante com Satiko tinha como objetivo garantir consequências para outros comportamentos da criança e, ao mesmo tempo, diminuir a probabilidade de que a mãe generalizasse para outros comportamentos a recomendação de não reagir às verbalizações sobre o espírito da avó.

Além da orientação à família, logo que as colegas chegaram, foi iniciada a parte lúdica, com a presença da mãe e do irmão, tendo o pai retornado a seus afazeres. A mãe foi instruída a observar as brincadeiras e identificar o que Satiko e suas amigas estavam fazendo quando o terapeuta as elogiava. As brincadeiras realizadas consistiram de:

- Quente frio: o terapeuta cochichava ao ouvido de Satiko para ela trazer um objeto não muito grande, retirado um de cada vez da sala, cozinha, de seu quarto ou do quarto dos pais, envolvidos em uma toalha para não serem identificados de imediato. Depois de fazer "suspense", pedia para uma das crianças esconder o objeto embrulhado na toalha, em algum local. O tera- peuta indicava a mesma sequência de ambientes (conforme a hierarquia do medo), porém repetindo alguns para garantir maior exposição de Satiko naquele local. Enquanto as crianças procuravam o objeto, o terapeuta oferecia dica de proximidade do local escondido, usando palavras, tais como quente, muito quente, quentíssimo, ou frio, muito frio e gelou para sinalizar distanciamento.

- Pinturas sobre a natureza: cada criança devia decidir qual seria a pintura, reproduzi-la em um cartão de mais ou menos $20 \times 15 \mathrm{~cm}$. Após o término, as pinturas eram sorteadas entre elas (ninguém ficaria com a própria pintura) para que colocassem em seus quartos.

Na sequência, Satiko servia chá para as amigas, que se despediam e retornavam às suas casas, como estava combinado. Após a saída das colegas, foi solicitado que Satiko escolhesse o lugar em seu quarto para colocar a pintura e, em seguida chamasse a mãe para ver como ficou o quarto. Satiko alterou a instrução recebida e, ao retornar, pediu para a mãe adivinhar onde ela havia colocado a figura.

Em outra sessão, as crianças realizaram primeiramente a tarefa escolar. Após isso, a atividade consistiu, conforme o combinado, em adivinhar o local em que cada uma delas havia colocado a pintura. Satiko perguntou ao terapeuta se podia mostrar seu quarto com a figura para as colegas. O terapeuta respondeu que sim e que o quarto devia estar mais bonito.

As brincadeiras foram repetidas em outras sessões, variando-se os objetos e graduando o tempo de permanência nos ambientes nos quais Satiko, anteriormente entrava com acompanhamento. Na brincadeira "quente frio", por exemplo, variou-se a condução, ora por uma das colegas, sorteada, e ora conduzida por Satiko. Outras brincadeiras com os "bonecos falantes" foram também repetidas, variando-se o conteúdo.

\section{Resultados e Discussão}

Os resultados do presente estudo são baseados nos registros feitos em um diário de campo, que incluía as observações do terapeuta e os relatos de alterações ambientais ocorridas em cada sessão. Os registros foram organizados de forma a identificar os comportamentos relacionados à avaliação inicial, bem como outros comportamentos que passaram a ocorrer nas sessões e no 
ambiente doméstico (observação e relato) e também na escola (relato).

A Figura 1 resume os comportamentos apresentados na queixa e comportamentos diferenciados, relacionados aos mesmos objetos. $O$ atendimento realizado pode ser considerado efetivo porque: a) o relato sobre a presença da avó ocorreu uma única vez no ambiente familiar e posteriormente, até o follow-up, não mais apareceu. Também deixaram de ocorrer outros comportamentos aparentemente relacionados a esse, como: esquivar-se de entrar em um ambiente (por medo) sem companhia, pedir a presença da mãe no próprio quarto até conciliar o sono, procurar o quarto dos pais para dormir, recusar-se a fazer as tarefas escolares com as amigas em sua casa, apresentar dificuldades escolares.

Por outro lado, foram registrados outros comportamentos, permitindo inferir que passaram a ser contingenciadas pelo ambiente Figura 1. Em outras palavras, as demandas geradas pela "ausência da avó" foram substituídas por outros comportamentos, consequenciados "naturalmente" pelo ambiente, tais como maior atenção do pai e do irmão às brincadeiras de Satiko, conversas entre mãe e filha sobre diferentes assuntos, maior envolvimento da menina com as tarefas escolares etc.

De maneira semelhante, outros ganhos decorrentes do atendimento beneficiaram os familiares, como

\section{$\square$}

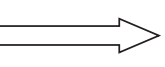

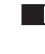

Dormir no quarto dos pais e irmão
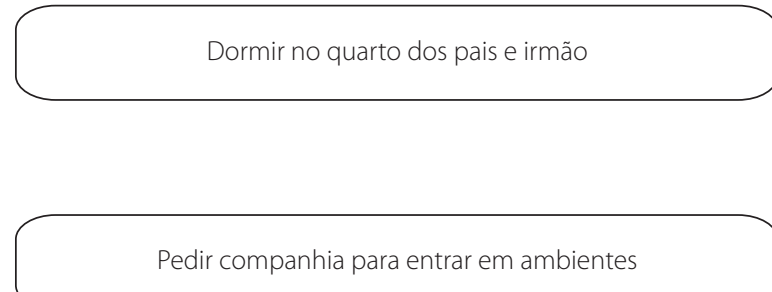

Pedir companhia para entrar em ambientes

Solicitar presença da mãe para dormir
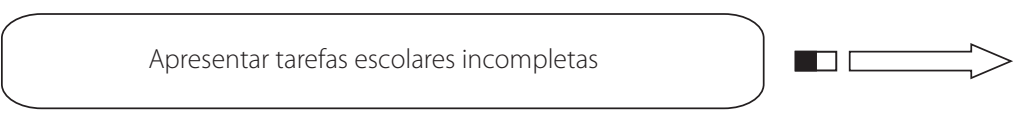

290 comportamentos que aumentaram em frequência.

Figura 1. Comportamentos iniciais (queixa) e comportamentos que deixaram de ocorrer, passaram a ocorrer sob outros controles ou outros

- Conversar outros assuntos sobre a avó

- Colocar foto da avó no porta-retrato

- Dormir em seu próprio quarto

- Enfeitar o próprio quarto
- Apresentar tarefas completas

- Participar de atividades

- Fazer mais amizades na escola

- Receber as amigas para tarefas em cas

- Brincar com amigas

- Servir chá e doces para amigas 
maior contato da mãe com as professoras e a escola, melhora no relacionamento entre Satiko e seu irmão, e maior participação do pai no processo familiar, prestando mais apoio à esposa.

Durante o período de atendimento houve, segundo relato da mãe, três falas sobre a avó. Na primeira, no café da manhã e na presença do irmão, Satiko referiu que havia visto a avó. Nem a mãe nem o irmão Ihe responderam, e ela então pegou a lancheira e a mochila, pedindo para o irmão se apressar. Na segunda menção à avó, a mãe informou que estava na hora do almoço. Satiko disse dirigindo-se ao pai: "A vó é que sabia fazer essa comida". O pai teria concordado, o que fez a mãe dizer: "Então eu não sei fazer, não faço mais" e todos riram. A terceira referência à avó foi relacionada à busca de Satiko por uma foto da avó para colocá-la em um porta-retrato em seu quarto.

No período do follow-up, já quase ao final do ano escolar, Satiko havia recuperado as notas e, segundo as professoras, tornara-se mais interessada nos estudos, mantendo as amizades que fazia; também parecia mais desembaraçada. A mãe disse que eventualmente falavam sobre a avó e Satiko parecia "ficar mais alegre", mas não voltara a fazer referência à presença do espírito. A orientação de dar atenção a Satiko, conversando sobre outros assuntos, parece ter sido importante para manter os comportamentos alternativos da criança.

Nas sessões lúdicas, tanto na clínica como na residência de Satiko, o terapeuta consequenciava positivamente comportamentos-alvos. A possibilidade da brincadeira estruturada pelo terapeuta para criar demandas para comportamentos-alvo vem sendo crescentemente explorada em contexto clínico (Del Prette, 2006, 2010; Vasconcelos, Cunha da Silva, Curado \& Galvão, 2004). No atendimento ora relatado, a brincadeira "quente-frio" possibilitou conduzir o processo de dessenssibilização sistemática, na hierarquia do menor medo até o maior. Havia a passagem para outro item da hierarquia quando não se observava nenhum temor no ponto de exposição em que Satiko se encontrava. Essa brincadeira expunha Satiko a diferentes modelos (crianças que modificavam sua orientação de busca em função de dicas ou testavam dicas modificando a direção). Esses comportamentos eram consequenciados pelo terapeuta. Além disso, Satiko passou pelo processo de modelagem para comportamentos de tomada de decisão nas brincadeiras, por exemplo, no início havia certa hesitação e espera que alguém tomasse à frente; aos poucos, suas tentativas de aproximação do ambiente se tornaram cada vez mais rápidas e foram consequenciadas (isso mesmo, ótimo, agora você foi mais rápida) até que ela, por várias vezes, tomasse a iniciativa.

Finalmente, um aspecto que parece relevante em atendimentos com esse tipo de problema na clínica se refere às crenças no sobrenatural ${ }^{4}$. A mãe, ao responder à filha "isso passa" e, ato contínuo, intensificar o ritual com as velas e orações, validava o relato da menina: algo pode "deixar de acontecer" porque aconteceu. Essa resposta da mãe "isso logo passa", certamente refletia a cultura de seu grupo. Adicionalmente, tanto a mãe como Satiko estavam expostas a outras práticas culturais (a "benzedura" católica e a sessão espírita) para solucionar o problema.

Nesse contexto, o terapeuta precisa refletir sobre quais são as práticas culturais subjacentes à queixa dessa natureza, mesmo supondo que "ver espírito" seja algo compensatório à saudade experimentada pela ausência daquele que se foi. Isso justifica a frase de Cervantes, no frontispício deste texto. Contudo, e de qualquer maneira, a tarefa do terapeuta não é a mesma do investigador e seu objetivo não é a de descobrir"verdades transcendentais" mas sim de auxiliar o paciente.

No presente caso, o atendimento ajudou Satiko e sua mãe a superarem um suposto acontecimento que poderia intervir no desenvolvimento da criança. Aparentemente simples, o caso em si poderia ganhar uma dimensão inesperada para os pais imigrantes, que se esforçavam para se ajustar a costumes e ideias estranhas às suas. Isso poderia se transformar em um problema mais presente e duradouro, com consequências imprevisíveis para Satiko e sua família.

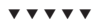

4 Vários psicólogos estudaram questões relacionadas à espiritualidade e ao sobrenatural (Goodwin, 2005, Jung, 1939, McDougall, 1927, Rhine, 1934, J. B. Rhine \& L. E. Rhine, 1929, Rhine \& McDougall, 1934). Esses fenômenos estavam presentes na academia e foram investigados do final do século XIX até meados do século XX. Não foram poucos os que aceitavam a sobrevivência e comunicação dos mortos, por exemplo, a William James é atribuída a frase: "Quanto mais vivo, mais cresce minha convicção da existência da imortalidade". 


\section{Referências}

Baum, W. M. (2006). Compreender o behaviorismo: comportamento, cultura e evolução. Porto Alegre: Artmed

Cole, M., \& Cole, S. R. (2003). O desenvolvimento da criança e do adolescente. Porto Alegre: Artmed.

Conte, F. C. S., \& Regra, J. A. G. (2000). A psicoterapia comportamental infantil: novos aspectos. In E. F. M. Silvares (Org.), Estudos de caso em psicologia clínica comportamental infantil (Vol. 1, pp.79-136). Campinas: Papirus.

Del Prette, A., \& Del Prette, Z. A. P. (1984). Tratamento de vômito psicogênico em uma criança. Psicologia: Ciência e Profissão, 4 (2), 34-38.

Del Prette, G. (2006). Terapia analítico-comportamental infantil: relações entre o brincar e comportamentos da terapeuta e da criança. Dissertação de mestrado não-publicada, Programa de Pós-Graduação em Psicologia Clínica. Universidade de São Paulo.

Del Prette, G. (2010). O que faz o terapeuta analítico-comportamental infantil: relações entre teoria e prática. Tese de doutorado não-publicada, Instituto de Psicologia, Universidade de São Paulo.

Del Prette, Z. A. P., \& Del Prette, A. (2009). Avaliação de habilidades sociais: bases conceituais, instrumentos e procedimentos. In A. Del Prette \& Z. A. P. Del Prette (Orgs.), Psicologia das habilidades sociais: diversidadeteórica e suas implicações (pp.187-229). Petrópolis: Vozes.

Edeinstein, B. A., \& Yoman, J. (2007). Entrevista comportamental. In V. E. Caballo (Org.), Manual de técnicas de terapia e modificação do comportamento (pp.583-663). São Paulo: Santos.
Goodwin, C. J. (2005). A história da moderna psicologia. São Paulo: Cultrix.

Jung, C. G. (1939). Phénomènes occultes. Paris: Montaigne.

McDougall, W. (1927). Na experiment for the testing of the hypothesis Lamarck. Journal of Psychology, 17, 267-304

Novak, G., \& Peláez, M. (2004). Child and adolescent development: abehavioral systems approach. London:Sage Publications.

Rhine, J. B., \& McDougall, W. (1934). Extra-sensory perception. Boston: Bruce Humphries.

Rhine, J. B., \& Rhine, L. E. (1929). One evening's observation of a mind-reading horse. Journal of Abnormal and Social Psychology, 23 (4), 449-466.

Souza, C. R., \& Baptista, C. P. (2001). Terapia cognitivo-comportamental com crianças. In B. Rangé (Org.), Psicoterapias cognitivo-comportamentais: um diálogo com a psiquiatria (pp.523-534). Porto Alegre: Artmed.

Vasconcelos, L. A., Cunha da Silva, C., Curado, E. M., \& Galvão, P. (2004). Estratégias lúdicas da terapia analítico-comportamental infantil: a literatura infantil Branca de Neve e os Sete Anões. In M. Z. S. Brandão, F. C. S. Conte, F. S. Brandão, V. K. Ingberman, V. L. M. da Silva \& S. M. Oliane (Orgs.), Sobre comportamento e cognição: contingências e metacontingências, contextos socioverbais e o comportamento do terapeuta (Vol. 13, pp.306-320). Santo André: ESETec.

Vermes, J. S. (2009). Do que é feito um terapeuta infantil. Boletim Paradigma, 4, 21-23.

Recebido em: 25/8/2010

Aprovado em: 27/9/2011 